\title{
Stress analysis of the cylinder block of a small compression ignition engine
}

The work contains calculations to determine the deformation and stress in the block of a currently produced small displacement compression ignition engine. It is also an attempt to introduce some modifications to reduce the mass of the calculated component. In the first step, based on measurements, the model of the engine block was developed. The Autodesk Inventor 2016 software was used. Two additional components were also designed to provide the block closure: a simplified cylinder head and an integrated main bearing support. All elements were imported to the Siemens NX 12 program. The calculations were carried out for different cylinders and different values of the combustion pressure. An attempt was made to introduce some modifications to reduce the weight of the calculated element.

Key words: Diesel engine, cylinder block, modelling, finite element method

\section{Introduction}

Nowadays we can observe intensive development of vehicles powered by electric motors. Such motors are fed with electricity both by energy stored in batteries charged externally and generated on the fly in the case of hybrid drivetrain units. The latter ones, in majority of the cases, make use of spark ignition combustion engines. However, American auto makers successfully use compression ignition engines (CI) in hybrid systems as power units for luxury cars. European automotive OEMs have introduced the $\mathrm{CI}$ engines to powering such type vehicles as well. These are engines of small displacement, which are also mounted in cars as a conventional source of power. In a passenger car, the engine operated at variable speeds and loads has to be lightweight, cheap in operation, and should provide a good power band. Due to the above factors, reduction of mass of engine components becomes a necessity. Components of crank and piston system have to be lightweight and because of frequently changing velocity should feature low moment of inertia; additionally forces which act on these elements frequently change their direction. The cylinder block, however, is the heaviest element of the engine. The cylinder block should be as stiff as possible to assure durability of the power unit. Methods of calculating the cylinder block which are used today enable full usage of available material. Implementation of the Finite Element Methods to the calculations has allowed considerable weight reduction of manufactured power units.

The cylinder block of a combustion engine is a component which integrates all of the mechanisms of the engine. Because of this, a lot of care has to be given in the process of designing this element, focusing mainly on its stiffness and mass, stiffness being the more important aspect of the two. A cylinder block serves as a support for main bearings of the crankshaft, enables kinematic positioning of pistons, as well as provides the mounting points for cooling and lubrication systems. The cylinder block also contains engine timing, chassis and gearbox mounting points. Floppy cylinder block can deform during engine operation - under changing and high loads - which in turn decreases the durability and reliability of the engine $[6,7]$.

Cylinder blocks of piston engines are manufactured from cast grey iron or aluminum-silicon alloys. Cylinder blocks for automotive engines of small swept capacity in majority of the cases are made of grey iron, cast as one element along with the cylinders. In such case a better grade of grey iron, with higher abrasion resistance should be used. An integrated main bearing support made out of cast aluminum-silicon alloy is then affixed to the engine block from underneath, usually along with a stamped steel oil pan screwed in. Such solution ensures required stiffness, optimal parameters in regards to noise, vibrations, harshness (NVH), and simplified manufacturing processes within limits of assumed dimensional limitations [2]. Manufacturing costs of a cylinder block are equal to about $10 \%$ of total engine costs, while costs of the material amounts to half of this value. Nowadays more methods of reducing manufacturing costs have surfaced, including modular engine design - e.g. designing an engine family consisting of 3- and 4-cylinder engines, which share pistons and conrods, and only slightly differ in dimensions of the crankshaft, cylinder block and cylinder head [1].

The study is devoted to calculations aimed at evaluation of strain and stress levels in cylinder block of a currently manufactured compression ignition engine of small swept capacity. It is also an attempt to introduce some modifications to reduce the mass of the calculated component.

\section{Object of the investigation and its modelling}

The analyses were performed for the cylinder block having the main technical parameters as specified in the Table 1 .

Table 1. Main technical parameters of the engine

\begin{tabular}{|c|c|c|}
\hline Engine & \multicolumn{2}{|c|}{$\begin{array}{l}\text { Compression ignition, turbocharged, common } \\
\text { rail system }\end{array}$} \\
\hline Swept capacity & $\mathrm{dm}^{3}$ & 1.248 \\
\hline Maximum power & $\mathrm{kW} / \mathrm{rpm}$ & $55.2 / 4000$ \\
\hline Maximum torque & $\mathrm{Nm} / \mathrm{rpm}$ & $190 / 1500$ \\
\hline
\end{tabular}

In the first stage of the work, the cylinder block has been prepared as a 3D model to be used later on in as a math model. The Autodesk Inventor 2016 program was used for this purpose. Great effort has been made to reproduce the most important dimensions of the cylinder block as accurately as possible. Selected view and cross-section are presented in the Fig. 1 and 2. 


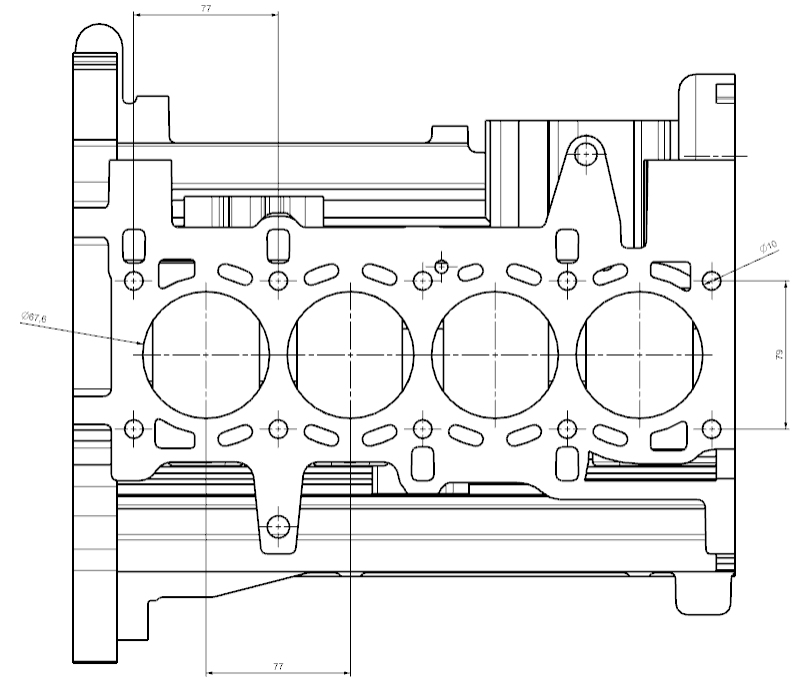

Fig. 1. Top view of the cylinder block

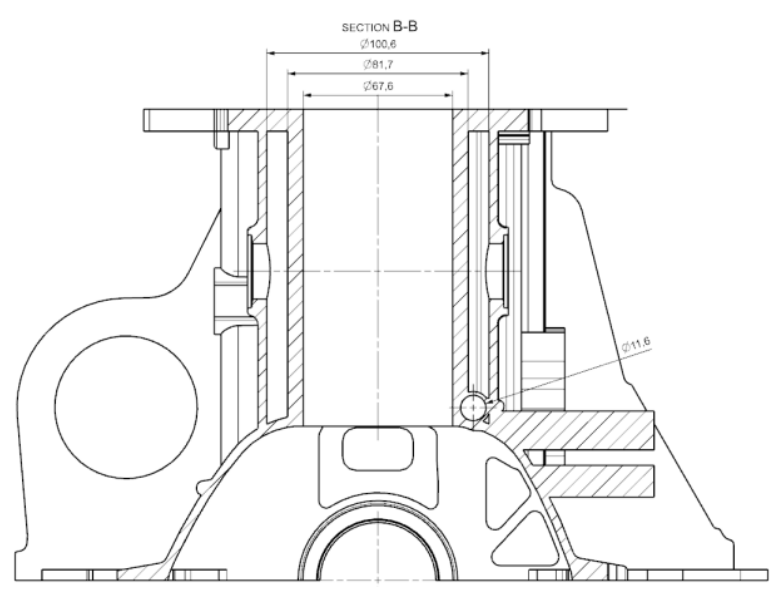

Fig. 2. Cross-section through the second cylinder's axis

Two additional elements have been modelled in the next stage, used as the closure of the cylinder block: simplified cylinder head and integrated main bearing support. Such elements were introduced to allow calculations of the screw connections between those components.

Prior to start of the FEM calculations it is necessary to prepare model suitable for such type calculations. Therefore, the model has to be simplified as much as possible without affecting the overall stiffness of the structure. It is a frequently used solution to shorten the calculation time. Features such as chamfers, small fillets and holes were removed. In case of the analyzed object most of these elements have been eliminated, however, oil channels and mounting points from both sides of the block, used to attach various engine components were not removed. The model prepared in such way was then imported to Siemens NX 12 software. Cylinder head and an integrated main bearing support were also modeled in this program for calculation purposes. View of the model prepared to the calculations is shown in the Fig. 3.

In the next step the size of the mesh was determined. In case of FEM calculations, using 3D elements as finite elements, the size of the elements has a very significant effect on duration of the calculations and their accuracy. The cylinder block, however, is a rather big element. In the end it has been decided to use an overall mesh size of $6 \mathrm{~mm}$, but using localized mesh density of $1 \mathrm{~mm}$, particularly around the screw mounting points. The mesh with the Jacobian matrix determinant of 10 was used.

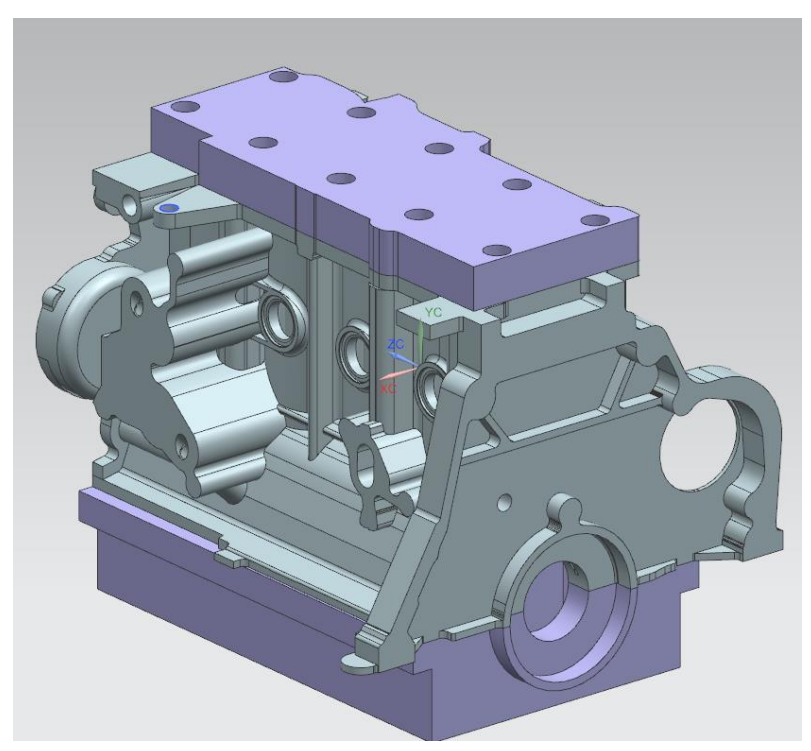

Fig. 3. Isometric view of the calculation model

\section{Properties of a CI engine cylinder block mathematical model}

The following constraints were placed upon the calculation phase:

- mesh elements of tetrahedral (10) type - triangle pyramids described by 10 nodes (vertices and central points of sides); mesh density $6 \mathrm{~mm}$,

- mesh density locally scaled down to $1 \mathrm{~mm}$, particularly around points where the loads were applied. Such step was necessary in order to shorten the duration of the calculations - in this configuration the FEM model took up to 4 hours to calculate,

- fixed constraints on elements of the cylinder block used to attach the engine - from front (Fig. 4) and rear side of the cylinder block,

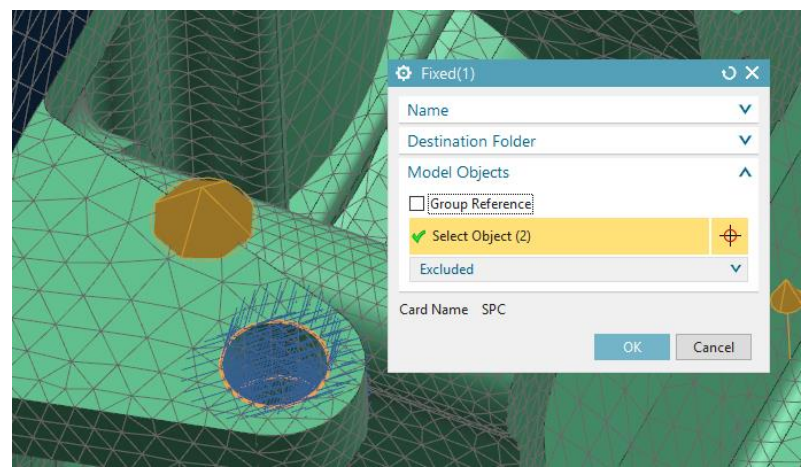

Fig. 4. Isometric projection of the calculation model

- contact between surfaces: cylinder block-cylinder head and cylinder block - integrated main bearing cover with friction coefficient of 0.3 (Fig. 5), 


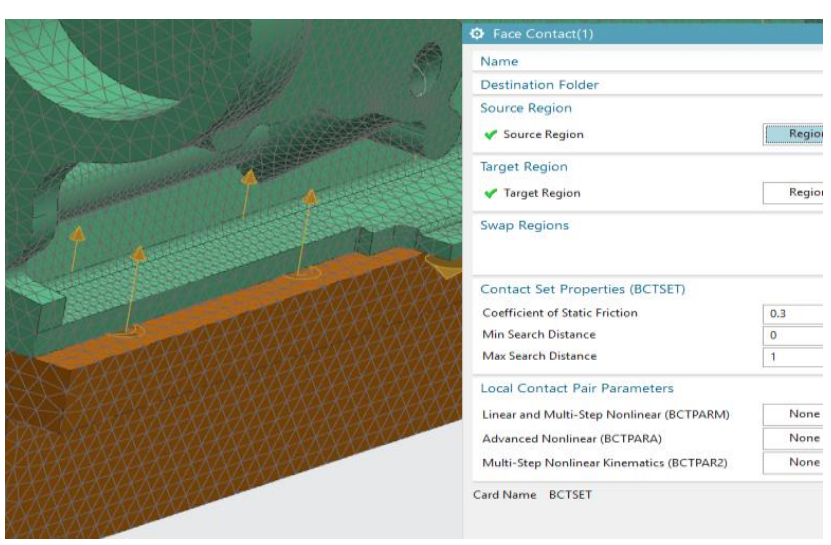

Fig. 5. Mating surface of the cylinder block with the main bearing cover

- maximum combustion pressure exerted on the surface of the cylinder head at $15 \mathrm{MPa}$ (Fig. 6),

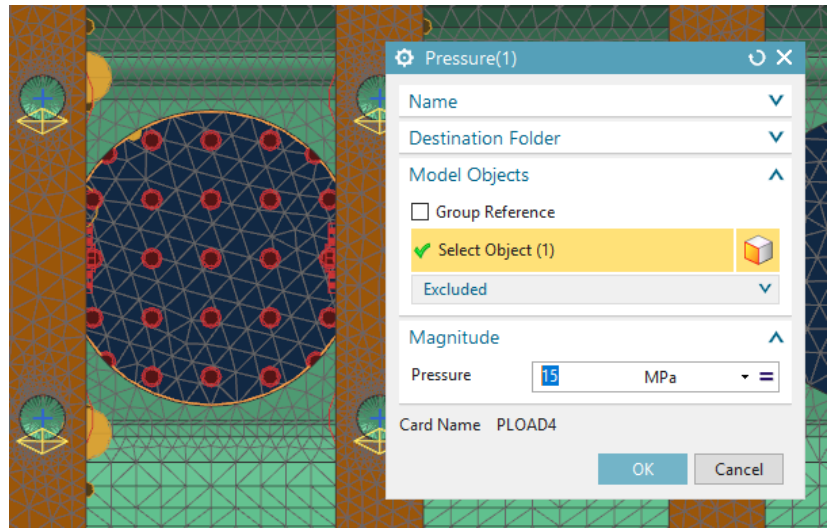

Fig. 6. Combustion pressure load placed upon the cylinder head - bottom view, along the cylinder axis

- cylinder head bolt pre-load of 22,000 N (Fig. 7),

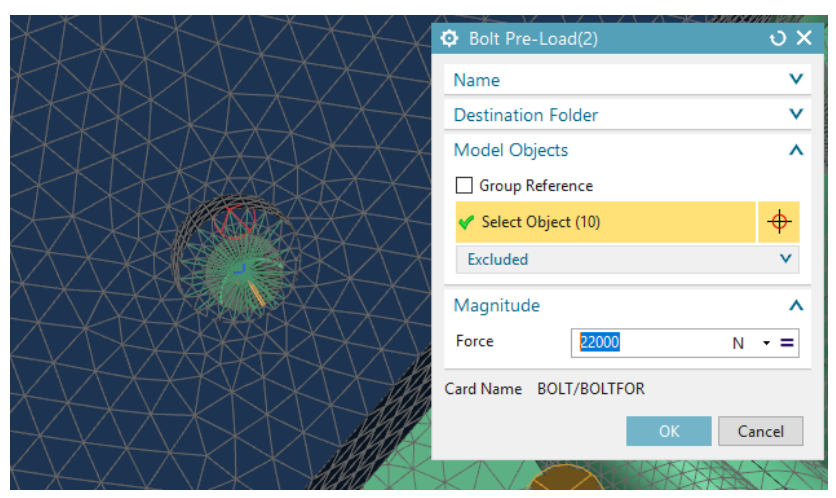

Fig. 7. Cylinder head bolt pre-load

- integrated main bearing support bolt pre-load at $12,000 \mathrm{~N}$,

- cylinder 1 main bearings laden with force of 28,750 N, equal to half the maximum gas force in the combustion chamber (Fig. 8),

- the presence of washers simulated in the bolt connection model (Fig. 9) has also been introduced. Such operation was done to reduce the number of points with local stress spikes far exceeding the expected values.

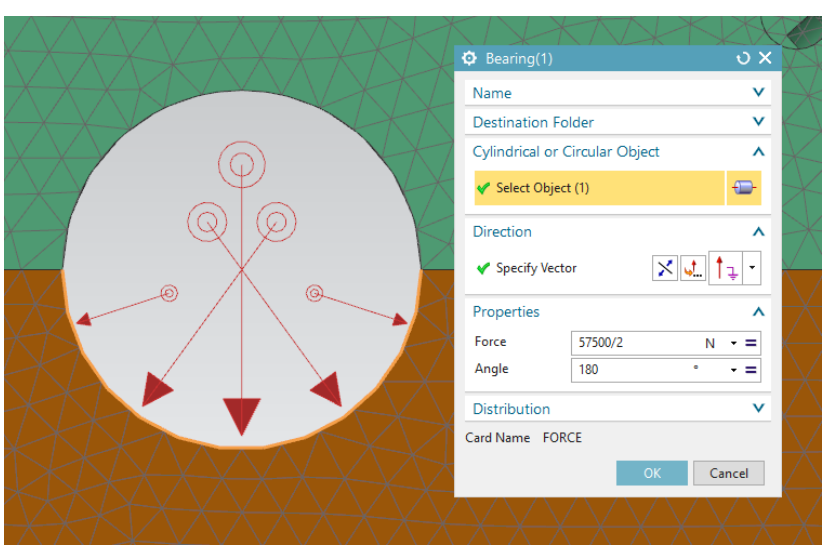

Fig. 8 Main bearing force load

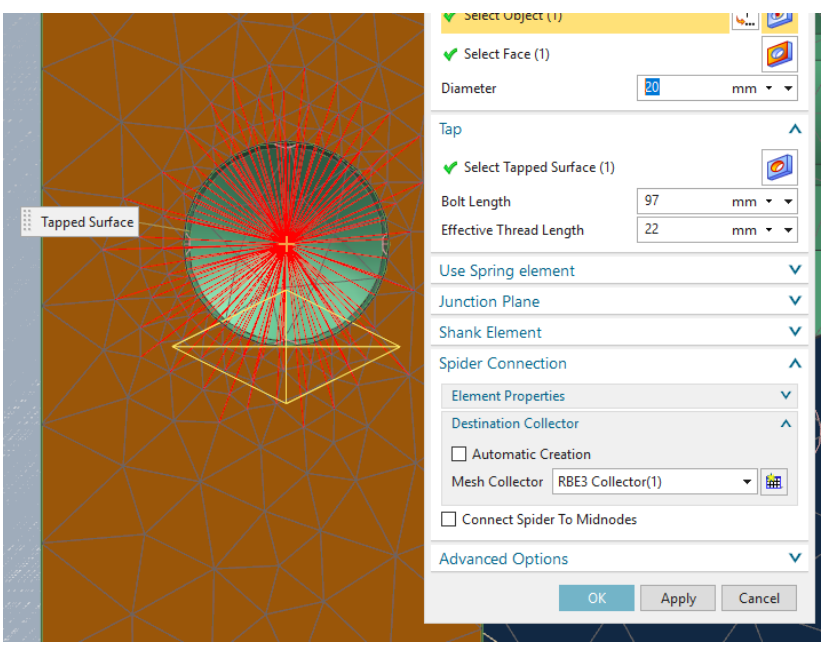

Fig. 9. Bolt connection model at the crankshaft main bearing support

\section{Results of the calculations}

Analysis of obtained results was performed after completion of the calculations. Maximum deformations have been spotted in the tightening area of the two central screws of the integrated main bearing support - they amount to $0.083 \mathrm{~mm}$ (Fig. 10).

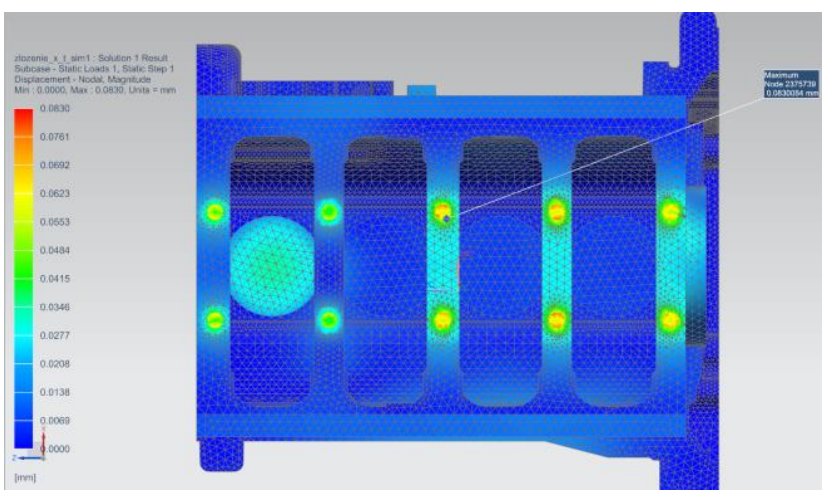

Fig. 10. Deformations of screw mounting points in the lower part of the cylinder block

In turn, the supporting points of the crankshaft in the closest location to the loaded cylinder were deformed with $0.007 \mathrm{~mm}$. Small deformations of the cylinder under the effect of exerted loads have also been noticed. These deformations amounted to $0.001 \mathrm{~mm}$ (Fig. 11). High stiffness 
in this area ensures durability of the engine and proper seal of the combustion chamber, which in turn assures a correct combustion cycle process and longevity of the engine. The smaller deformations of the cylinder, the lower risk of damage to the crankshaft-piston system, and the lower the risk of blow-by from the combustion chamber to the crankcase.

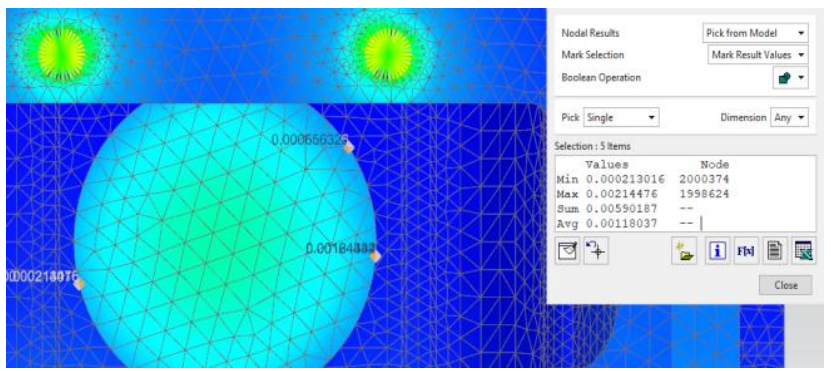

Fig. 11. Deformation of engine's cylinder

The deformations in the area of the connection between the cylinder head and the cylinder block are not considerable, their maximum value amounts to $0.01 \mathrm{~mm}$.

Reduced von Mises stresses were also analyzed. The support points of the crankshaft are not heavily stressed the mean stresses are equal to $29 \mathrm{MPa}$, while the maximum ones amount to $44.93 \mathrm{MPa}$. However, in the nodes where the screws of the integrated main bearing cover were tightened, occurrences of considerable stress spikes has been noticed. Further analysis of the stress values in these nodes it can be noticed that the smaller individual elements of the model, the higher the stress. This is the problem caused by so called FEM Singularity (Fig. 12).

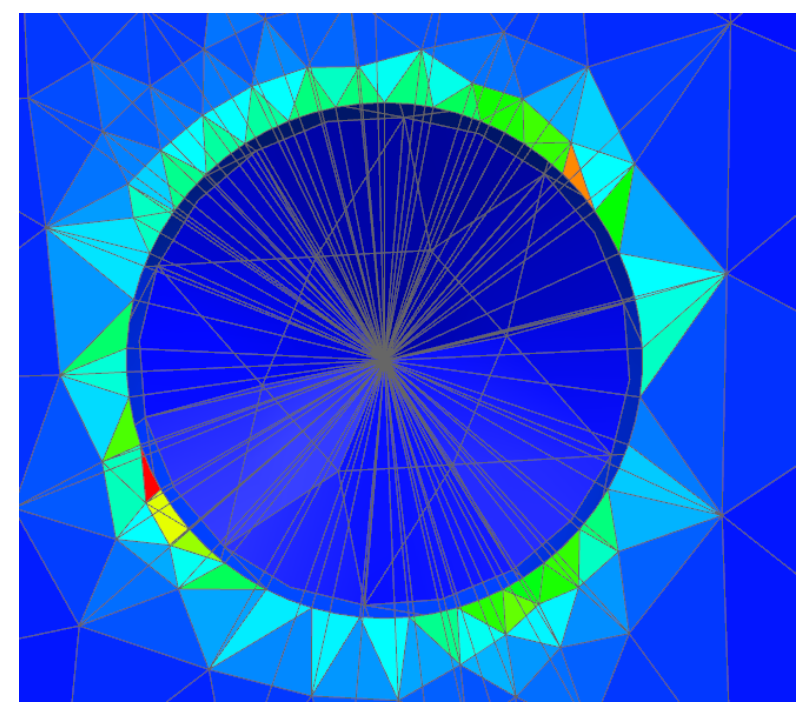

Fig. 12. Stress of the screw connection of the third mounting point of the integrated main bearing support

Such singularities usually occur in areas of sharp breakdown of edges and point-type loads. This can be caused by the method of modelling of the screw connections. In case of the analyzed calculation model, the Bolt Connection function in the NX program was used; this function connects finite element nodes laying on predefined diameter around the axis of the screw connection, to which the force was applied. Thus, it isn't applied as uniform pressure, but rather as a series of point loads [3-5]. In the literature we can often find statements about possibility of neglecting the stress spikes present in these nodes [3, 4]. In the Fig. 12 the highest obtained nodal values of the stresses are equal to $1182 \mathrm{MPa}$. However, in the adjacent elements the stresses amount to $220 \mathrm{MPa}$. Bigger elements connected with edge of the hole feature stress levels amounting at average to $180 \mathrm{MPa}$. It should be remembered, however, that the performed simulation assumes using screws with head flanges. The washers themselves were not taken into consideration, which in this case would take over a part of the stress.

The thread in the tightening area of the screws of the cylinder head is subjected to stress of $115 \mathrm{MPa}$ at the average. Lower stresses - at the average $51 \mathrm{MPa}$ - have been observed on the threads of the screws the integrated main bearing cover. Axial stress in the screws of the cylinder head of the first cylinder are equal to $76 \mathrm{MPa}$ at the average (Fig. 13). The screws of the other cylinders are a little bit less stressed; in these areas the stress amounts to $69 \mathrm{MPa}$ at the average.

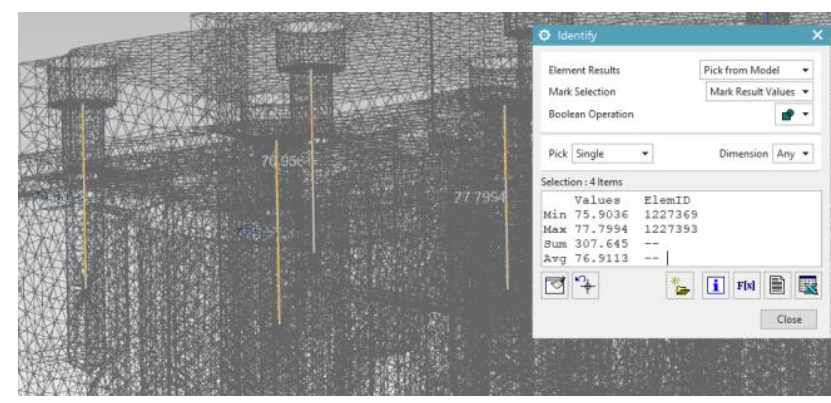

Fig. 13. Axial stress in screws of the cylinder head

The stress in the screws in the integrated main bearing support around the mounting area of the first cylinder amount to $79 \mathrm{MPa}$ at the average. Like in the cylinder head, the stress of other screws reaches an average value of $70 \mathrm{MPa}$. In case of both screws it is enough to use screws of 8.8 class, having a tensile strength of $800 \mathrm{MPa}$, and yield strength of $640 \mathrm{MPa}$.

\section{Modification proposals}

In the course of the calculations it has been confirmed that the cylinder block in question is not significantly stressed. Therefore, considerations were performed to determine the possibility of increased efficiency of available material. These were performed bi-directionally. The first attempt was made to reduce the mass of the cylinder block. In the second attempt, the maximum pressure in the combustion chamber has been increased in course of the calculations.

Modification of the dimensions of the cylinder block is difficult due to a few reasons. The modifications often necessitate a modification of other elements, which in turn could lead to the need of modifications of other components mounted on the cylinder block. In the end, with slight changes to the thickness of external walls, with modified reinforcements on the cylinder block, and reducing thickness of mounting areas of the crankshaft, the mass of the cylinder block was reduced from $34.17 \mathrm{~kg}$ to $31.2 \mathrm{~kg}$, what denotes reduction of materials demand to production of the cylinder block with o $9.7 \%$. It should be underlined that the 
modifications were introduced in areas with the lowest load. The authors are aware, however, that fatigue and thermal stresses were not taken into considerations in presented here paper, the calculations were made for a single stroke of engine operation only. Difference in the manufacturing technology of the block have to be taken into account as well.

To assess a possibility of increasing pressure in combustion chamber, the maximum combustion pressure has been increased to $20 \mathrm{MPa}$ in the mathematical model. The load on the main bearing mounting points has been increased to $76,100 \mathrm{~N}$. After analyzing the results it has been noticed that the deformations of the cylinder walls have remained at the same level as before, in the lower-stressed version. Stresses in supporting areas of the crankshaft were slightly increased, now reaching value $30 \mathrm{MPa}$ at the average and $51 \mathrm{MPa}$ at the maximum. Previously these values were equal to 29 and $44 \mathrm{MPa}$ respectively. In spite of changed pressure acting on the base plate of the crankshaft, the maximum stresses remained unchanged and were still at the level of $1182 \mathrm{MPa}$. Also in this case the problem connected with singularity of the FEM methods - individual nodes with very high stresses, potentially growing up to infinity has been noticed. Axial stresses in screws of the cylinder head have increased - at the average now they amount to $82 \mathrm{MPa}$, and to $83 \mathrm{MPa}$ at the maximum. In lower part of the cylinder block the screws are more heavily loaded. Average stress amounts now to $82.9 \mathrm{MPa}$.

\section{Summary}

After completion of the calculations it should be stated that the cylinder block in question was designed so as to avoid any excessive values of the stresses. The stiffness was guaranteed owing to suitable thickness of walls and reinforcements connecting the upper plate with lower part of the cylinder block. Knowing that, more attention should be paid to connection points with the cylinder head. Considerable values of stresses in nodes where the screws are tightened have been found several times in course of the calculations. Even in case when singularities of the FEM method are neglected in this area, the stresses reach high levels. This dictates a necessity to extend calculations performed up-to-now with analyses, which would take into considerations completely modelled cylinder head of the analyzed engine. The same issue concerns the unified crankshaft main bearing support (i.e. so called bed plate).

Engines of passenger cars are exposed both to changing mechanical and thermal loads. Both the material fatigue and thermal load have not been taken into consideration in this case. However, it seems possible to increase mechanical load of the cylinder block without modification of its dimensions.

The authors consciously did not take into account the influence of temperature in the calculations. However, the presented considerations are the first part of the work on stress analysis of the engine block. In the next part, the authors will carry out calculations taking into account the previously mentioned supplements and thermal loads. The results will be used to assess the possibility of further reducing the weight of the elements and in the didactic process.

In spite of accuracy offered by modern engineering calculation tools using FEM methods, each engine is intensively tested in prototyping phase with respect to its mechanical and thermal strength. It is always necessary to take into considerations material changes arisen during machining operations, in relation to idealized computer model. This problem concerns engine elements exposed to friction force and thermal loads mainly. These processes enable final assessment of the product. The achieved results, however, pave way to a future possibility in creating different versions of the engine based on the same cylinder block, for example a more powerful version of the engine.

\section{Nomenclature}

FEM finite element method

CI compression ignition engines

DI direct injection

NVH noise, vibrations, harshness

OEM original equipment manufacturer

\section{Bibliography}

[1] EGERT, M., CARTELLIERI, W., VEIT, U., WALTER, R. Latest design and development aspects of engines for light commercial vehicles to meet future emission limits. F1SITA World Automotive Congress. Sept. 27-Oct. 1, 1998.

[2] IMARISIO, R., PAPA, P.G., SIRACUSA, M. The new Fiat GM Powertrain small diesel engine. 12. Aachener Kolloquium Fahrzeug- und Motorentechnik. 2003, 141-155.

[3] Stress singularities and concentrations - Mesh convergence in FEA https://www.linkedin.com/pulse/stress-singularitiesconcentrations-mesh-fea-marcos-ac\%C3\%ADngonz\%C3\% A1lez.

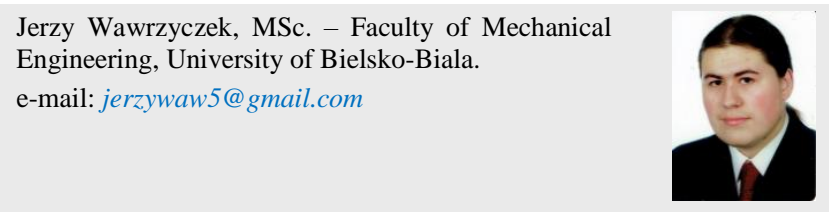

[4] Singularities in Finite Element Models: Dealing with Red Spots. https://www.comsol.com/blogs/singularities-in-finiteelement-models-dealing-with-red-spots.

[5] Stress singularity - an honest discussion. https://enterfea.com/ stress-singularity-an-honest-discussion.

[6] WAJAND, J.A., WAJAND, J.T. Tłokowe silniki spalinowe średnio- i szybkoobrotowe. WNT. Warszawa 2005.

[7] ZHANG, W., CAO, X. Structure analysis and improvement of diesel engine block. 2nd International Conference on Electronic \& Mechanical Engineering and Information Technology. 2012, 1610-1613.

Tomasz Knefel, DSc., DEng. - Faculty of Mechanical Engineering and Computer Science, University of Bielsko-Biala.

e-mail:knefel@ath.bielsko.pl 